\title{
Improved DC-Link Voltage Controller for Photo Voltaic ON-Grid Systems
}

\author{
Husain A. Ismail ${ }^{1}$, Ahmed Alenany ${ }^{2}$, and Belal Abozalam ${ }^{3}$ \\ ${ }^{1}$ Department of Electronics and Control Engineering, Belbeis High Institute for Engineering, Belbeis, Sharkia, Egypt \\ ${ }^{2}$ Department of Computer and Systems Engineering, Zagazig University, Egypt \\ ${ }^{3}$ Department of Industrial Electronics and Control Engineering, Menoufia University, Egypt
}

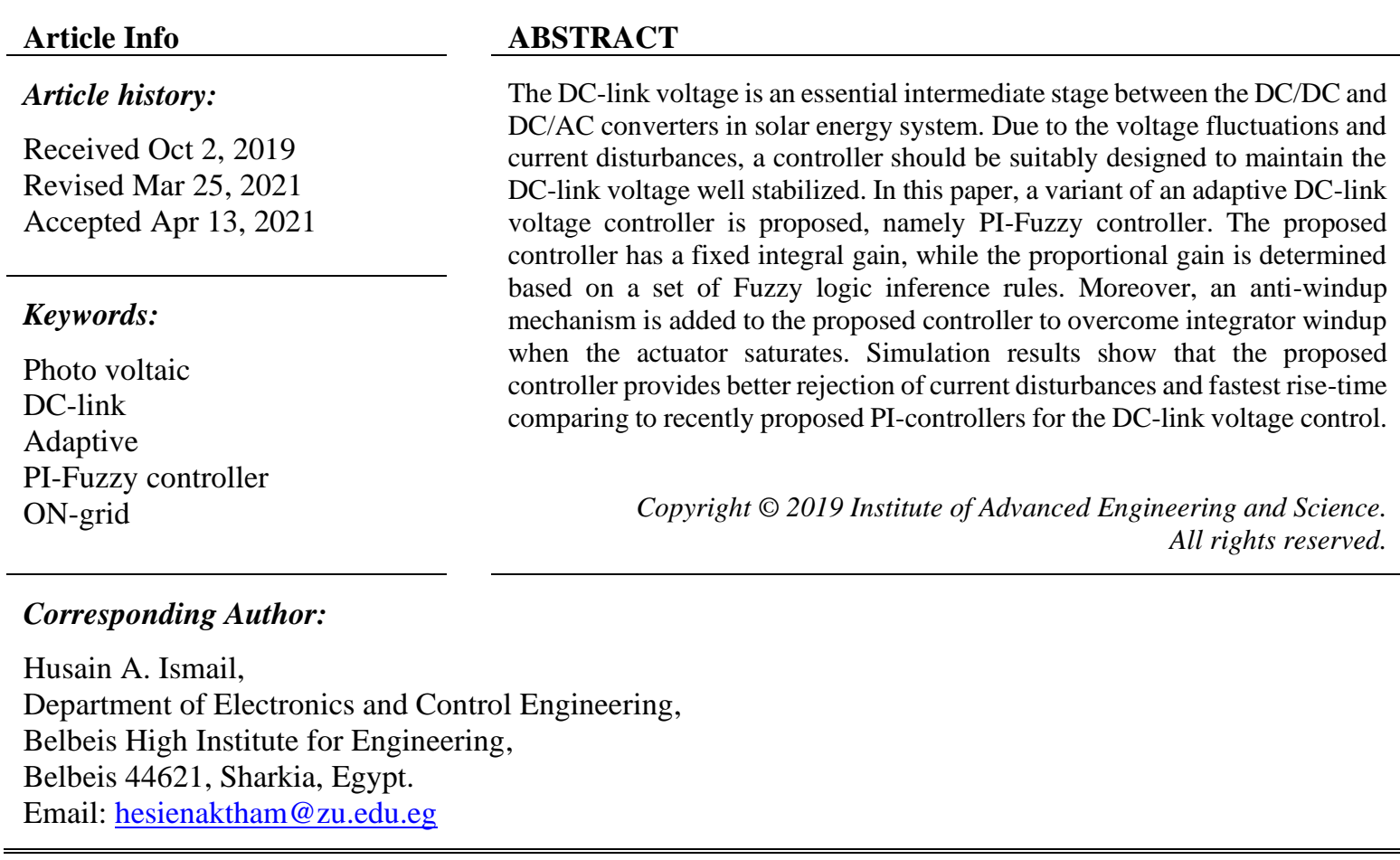

\section{INTRODUCTION}

Renewable energy resources, such as solar, wind, and hydroelectricity, are promising alternatives to traditional energy resources, e.g. oil and gas which are known to be limited, costly, contaminate the environment, and increase global warming. Solar energy can be converted to electrical energy using photo voltaic (PV) panel which is then converted to three phase sinusoidal voltages by means of three phase inverters. The output of the PV panel is DC-voltage that is converted into AC-voltage using power converters. The DClink which is an intermediate stage between the passive filter and grid connected converters (GCC) is an essential part in the conversion process of the power from DC to AC. Such dc-link exist, for example in UPS systems [1], renewable energy sources [2], [3], back-to-back systems [4], [5], and adjustable speed drives [4], [6]. It should be noted that there are several sources of disturbances that may be introduced in the PV on-grid system. For instance, grid voltage distortion, non-ideal characteristics of power switches, dead band of pulse width modulation, device turn on/off, and DC offset and scaling errors in measuring currents and voltages [7]. These disturbances lead to degrading the power quality of PV on-grid systems. However, it is difficult to tackle all these issues in one work. In this paper, we focus on the disturbances on the DC-Link voltage caused by grid voltage distortion and device turn on/off.

Consequently, designing efficient DC-link voltage controller is important for many industrial applications to reduce the AC-voltage ripples resulting from random changes in the GCC loads.

The standard proportional-integral (PI) has been widely used in DC-link voltage controllers to provide an efficient DC-link [8], [9]. The PI gains have been adjusted based on the following requirements: stability, dynamic performance, disturbance rejection, and low-overshoot in the step response. Manual adjustment of standard PI controller is not feasible due to rapid changes in the operating conditions. Therefore, self-tuned or adaptive PI controller has been proposed in [10]-[14] to adjust PI gains automatically based on the operating 
condition changes. In [15], [16], feed-forward compensation method is combined with PI controller to provide an efficient DC-link voltage control. It provides a good dynamic performance; however, these kinds of controllers increase the coupling effect between the grid current and DC-link voltage. Thus, any rapid changes in the grid currents could produce ripples at the output reference of the DC-link voltage controller. An adaptive PI controller with anti-windup is recently proposed in [17] to improve the DC-link controller performance by changing the PI gains in two regions. The first region is near the desired DC-Link reference voltage, in which the values of $K_{p}$ and $K_{i}$ are adaptively changing according to a predetermined mathematical equation as a function of the magnitude of the error between measured and reference values. In the second region, which is far from the desired DC-link reference voltage, the values of $K_{p}$ and $K_{i}$ are fixed. It has excellent performance in terms of stability, immunity to large disturbance, low overshoot at step input, and low total harmonic distortion (THD) at grid voltages.

Recently, PID Fuzzy Logic-based Controller (FLC) becomes widely used to deal with nonlinear systems that conventional PID is not very efficient to deal with. In [18], fuzzy logic with the classical PI controller was proposed to control the reactive power of PV inverter in an off-grid hybrid power system. In [19], a PID controller based on FLC was compared with the regular PID based on ZN for a set of point weight tunings. In [20], two advanced controllers based on fuzzy logic were used for performance improvement; one of them, called FSPI (fuzzy supervised conventional PI), was used to tune PI controller parameters using FLC. In [21], a comparison between the conventional PID and FLC-PID was carried out in the DC motor positioning system.

In this paper, a PI-Fuzzy controller is proposed for DC-Link voltage controller in PV connected to the power grid system. Instead of regular pole-placement gains calculations, the knowledge of the system's mathematical model is used to build if-then rules using fuzzy logic to adaptively change the controller gains to improve the dynamic performance of the DC-link voltage controller. It should be noted that the value of $\mathrm{Ki}$ is kept constant while the value of $K_{p}$ is adaptively determined based on a fuzzy logic all over the dynamic response. Furthermore, an anti-windup circuit is proposed to overcome the saturation problem caused by integral to suppress overshoots of the DC-Link voltage, especially after step jumps of the DC-Link reference voltage. A simulation comparison has been held between PI controllers in [17] and the proposed PI-Fuzzy controller to verify the superiority of the proposed controller under different operating scenarios, such as varying a step input and disturbance level. The proposed controller provides better stability, lower overshoot, and is more immune to large disturbances, compared to several recently proposed controllers in the literature.

The paper is organized as follows: Section 2 presents a model describing the DC-link voltage controller. In Section 3, the proposed PI-Fuzzy controller is introduced. Simulation results are presented in Section 4. Finally, the paper is concluded in Section 5.

\section{SYSTEM MODEL OF THE DC-LINK VOLTAGE CONTROLLER}

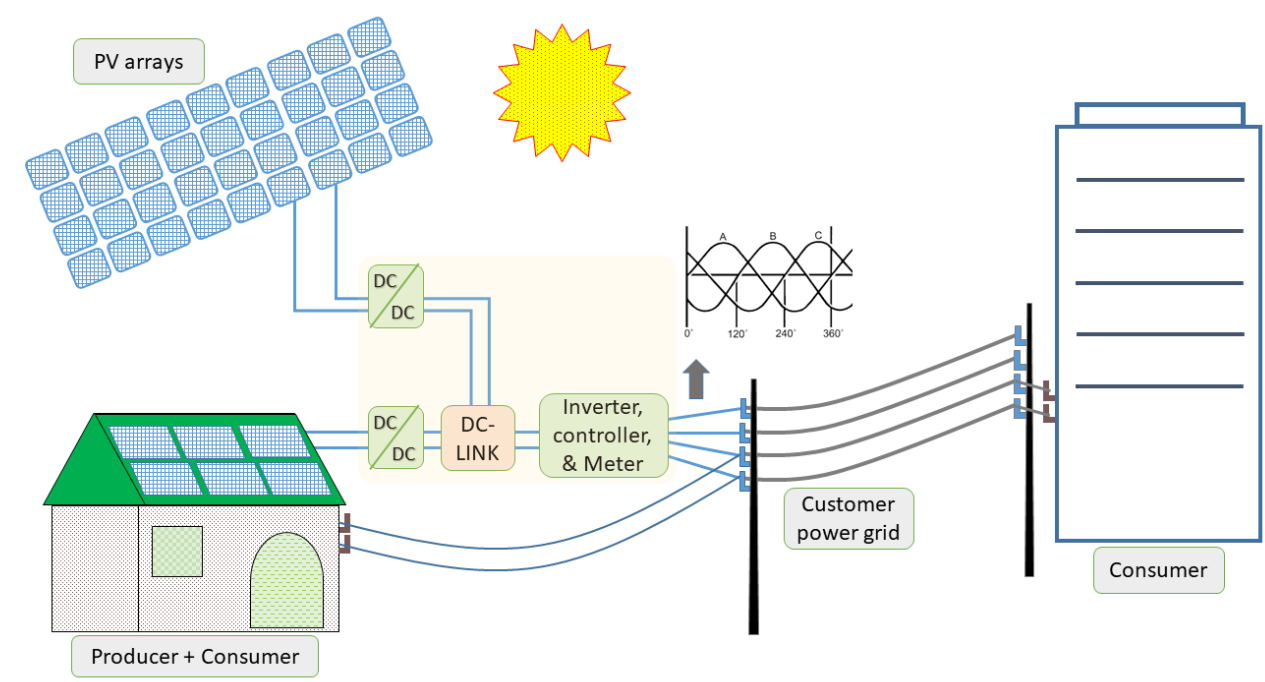

Figure 1. Power grid over solar energy model.

\subsection{Power Grid Over Solar Energy}

The connection of a solar panel to the electric grid is shown in Figure 1. The PV panel converts the solar energy into DC electric voltage. The DC/DC-converter converts the DC-voltage obtained by the PV panels to the desired reference voltage which is required for the AC inverter. The DC-link consists of passive 
capacitive or inductive elements between the two stages of the converter and acts as energy storage; it blocks the effect of grid power disturbances on the source side. The AC inverter converts the DC-voltage to the required three-phase voltage that is connected to the power grid. It should be noted that the output voltage of the AC inverter should have the same magnitude and frequency of the customer power grid.

\subsection{The DC-Link Voltage Controller}

As mentioned before, the DC-link consists of passive elements that store the energy between the DC/DC and DC/AC converters. The DC-link provides reliability and compactness for the two-stage converters [22], [23]. It also decouples the AC components which can occur from the PV panels to maintain the desired DC reference voltage of the DC/AC inverter input [24], [25].

The grid connected controller has three main functions: grid synchronization [26], grid current controller [27], and DC-link voltage controller [9]. In this paper, we focus on the DC-link voltage controller whose block diagram is illustrated in Figure 2. The capacitor $C$ refers to the DC-link capacitor, $V_{g(a, b, c)}$ represents the three-phase voltages in the natural reference frame, $i_{g(a, b, c)}$ is the three-phase currents in the natural references frame, $V_{d c}$ is the DC-link voltage, $V_{d c}^{*}$ denotes the DC-link voltage reference, $i_{d c}$ refers to the current coming out from the DC/AC converter, $i_{c}$ is the current through the DC-link capacitor, $i$ represents the current consumed/generated by PV panels, and $i_{g(d, q)}^{*}$ is the grid current reference in the synchronous reference frame which consists of two components, $i_{g d}^{*}$ and $i_{g q}^{*}$.

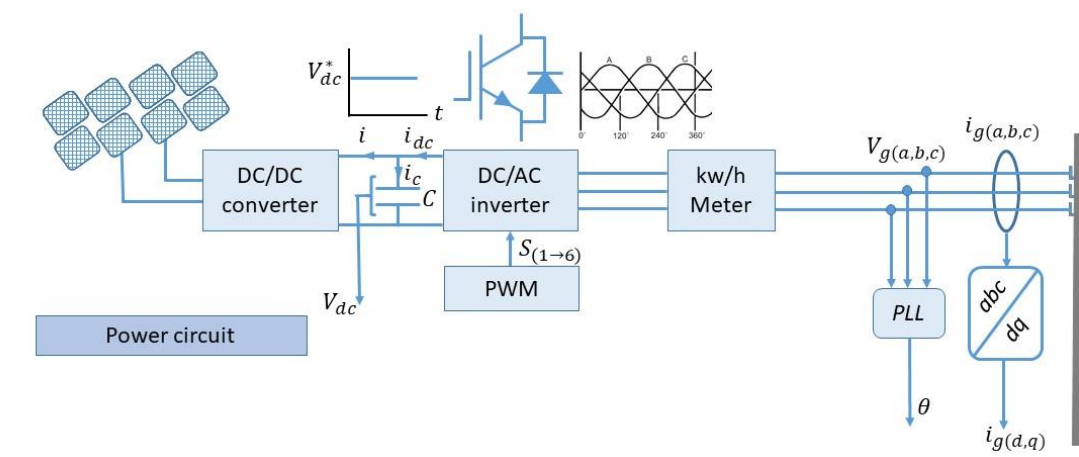

control circuit

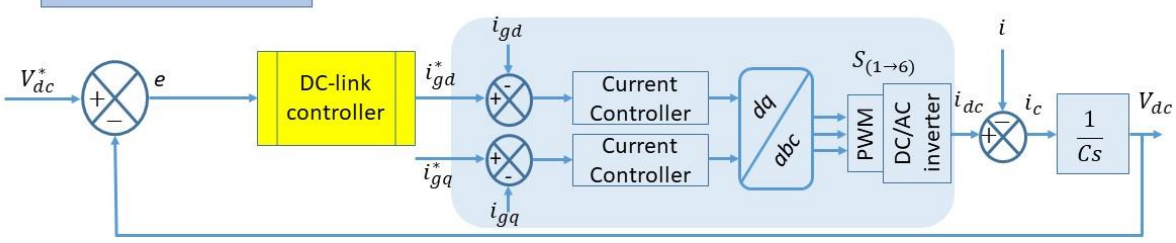

Figure 2. DC-link controller block diagram.

The relation between $i_{d c}^{\text {mean }}$ and $i_{g d}^{*}$ is given by [16]

$$
\begin{aligned}
& P_{A C}=\frac{3}{2} V_{g m} i_{g d} \approx \frac{3}{2} V_{g m} i_{g d}^{*} \\
& P_{D C}=V_{d c} i_{d c}^{\text {mean }}
\end{aligned}
$$

where, $P_{A C}$ and $P_{D C}$ are the active power fed into the AC and DC sides of the grid connected converter, respectively, $V_{g m}$ is the magnitude of phase voltage, and $i_{g d}$ is the d-component of the grid current.

By neglecting the power losses, it can be assumed that $V_{d c} \approx V_{d c}^{*}$. Hence, equating (1) and (2) (i.e., $P_{A C} \approx P_{D C}$ ), we obtain

where $G \approx \frac{i_{d c}^{\text {mean }}}{i_{g d}^{*}}$, is a pure gain.

$$
i_{d c}^{\text {mean }} \approx \frac{3}{2} \frac{V_{g m}}{V_{d c}^{*}} i_{g d}^{*}=G i_{g d}^{*} .
$$

To simplify the grid-connected controller model, it is assumed that system non-linearity is neglected, and the current control loop is much faster than the DC-link voltage control loop [1]. In this way, the current control loop can be represented as a gain $G$ inside the DC-link voltage control loop. 
In order to use a PI-controller for the DC-link voltage control, we have to find the proportional and integral gains (i.e., $K_{p d c}$ and $K_{i d c}$ ) using, e.g., pole-placement method. In the block diagram in Figure 2, there are two inputs, the reference voltage $V_{d c}^{*}$ and the current disturbance $i$. Using superposition, we can study separately the effect of each of these two inputs. The transfer function of the DC-link PI voltage controller is given as follows:

$$
G_{P I}=K_{p d c}+K_{i d c} / s
$$

Using superposition, the closed-loop transfer from input reference voltage $V_{d c}^{*}$ to output DC-link capacitor voltage $V_{d c}$ using PI-controller is obtained as

$$
\frac{V_{d c}}{V_{d c}^{*}}=\frac{\frac{G K_{p d c}}{C} s+\frac{G K_{i d c}}{C}}{s^{2}+\frac{G K_{p d c}}{C} s+\frac{G K_{i d c}}{C}}=\frac{2 \xi \omega_{n} s+\omega_{n}^{2}}{s^{2}+2 \xi \omega_{n} s+\omega_{n}^{2}}
$$

Where $\xi$ is the damping ratio, $\omega_{n}$ is the undamped natural frequency of the system and $G$ is a pure gain in (3), On the other hand, the closed-loop transfer from disturbance current $i_{\text {dis }}$ to output DC-link capacitor voltage $V_{d c}$ takes the following form:

$$
\frac{V_{d c}}{i}=\frac{-\frac{1}{C} s}{s^{2}+\frac{G K_{p d c}}{C} s+\frac{G K_{i d c}}{C}}=\frac{-\frac{1}{C} s}{s^{2}+2 \xi \omega_{n} s+\omega_{n}^{2}}
$$

Pole placement technique can be applied to (5) and (6) by equating the denominator polynomial coefficients to those of the standard second-order system. This gives

$$
\begin{aligned}
& K_{p d c}=\frac{2 C \xi \omega_{n}}{G} \\
& K_{i d c}=\frac{C \omega_{n}^{2}}{G}
\end{aligned}
$$

The poles of the transfer functions in (5) and (6) can be calculated as

$$
P_{(1,2)}=-\xi \omega_{n} \pm j \omega_{n} \sqrt{1-\xi^{2}} \quad 0 \leq \xi \leq 1
$$

In order for the system to be stable, the damping ratio $\xi$ must be positive. Therefore, both controller gains $K_{p d c}$ and $K_{i d c}$ must be positive.

To study the dynamic performance of the DC-link voltage controller, the peak time and maximum over-shoot of the DC-link voltage controller should be studied under the effect of changing the reference voltage and current disturbance.

In the case of changing the DC-link reference voltage, the voltage response is given by

$$
\begin{aligned}
V_{d c}(t)=V_{d c}^{\text {init }}+ & \left(1+\frac{2 \xi}{\sqrt{1-\xi^{2}}} e^{-\xi \omega_{n} t} \sin \left(\omega_{n} \sqrt{1-\xi^{2}} t\right)\right. \\
& \left.-\frac{1}{\sqrt{1-\xi^{2}}} e^{-\xi \omega_{n} t} \sin \left(\omega_{n} \sqrt{1-\xi^{2}} t+\phi\right)\right)\left(V_{d c}^{*}-V_{d c}^{\text {init }}\right)
\end{aligned}
$$

where the $V_{d c}^{\text {init }}$ is the initial value of the DC-link voltage and $\phi=\cos ^{-1} \xi$. By differentiating (10) and equating the results to zero, the peak time, $t_{\text {peak }}$, and maximum over-shoot, $M_{0}$, are given by

$$
\begin{aligned}
& t_{\text {peak }}=\frac{f_{1}(\xi)}{\omega_{n}} \\
& M_{0}=V_{d c}\left(t_{\text {peak }}\right)-V_{d c}^{*}=f_{2}(\xi)\left(V_{d c}^{*}-V_{d c}^{\text {init }}\right)
\end{aligned}
$$

where $f_{1}(\xi)$ and $f_{2}(\xi)$ are given by (13) and (14), respectively.

$$
\begin{aligned}
& f_{1}(\xi)=\frac{1}{\sqrt{1-\xi^{2}}} \tan ^{-1}\left(\frac{2 \xi+\frac{\xi}{\sqrt{1-\xi^{2}}} \sin (\phi)-\cos (\phi)}{-\frac{2 \xi^{2}}{\sqrt{1-\xi^{2}}}+\frac{\xi}{\sqrt{1-\xi^{2}}} \cos (\phi)+\sin (\phi)}\right) \\
& f_{2}(\xi)=\frac{e^{-\xi f_{1}(\xi)}}{\sqrt{1-\xi^{2}}}\left(2 \xi \sin \left(\sqrt{1-\xi^{2}} f_{1}(\xi)\right)\right)-\sin \left(\sqrt{1-\xi^{2}} f_{1}(\xi)+\phi\right)
\end{aligned}
$$

It can be seen that by increasing $\omega_{n}$ in (11), the peak time decreases which provides better dynamic performance. 

is given by

In the case of the occurrence a current disturbance due to the voltage fluctuations, the voltage response

$$
V_{d c}(t)=V_{d c}^{*}-\frac{I_{\max }}{C \omega_{n} \sqrt{1-\xi^{2}}} e^{-\xi \omega_{n} t} \sin \left(\omega_{n} \sqrt{1-\xi^{2}} t\right)
$$

where $I_{\max }=P_{\max } / V_{d c}^{*}$ and $P_{\max }$ is the maximum power generated/consumed by the PV panels. Similar to (11) and (12), the peak time and over-shoot are given by

$$
\begin{aligned}
& t_{p}=\frac{1}{\omega_{n}} \frac{1}{\sqrt{1-\xi^{2}}} \tan ^{-1}\left(\frac{\sqrt{1-\xi^{2}}}{\xi}\right)=\frac{f_{3}(\xi)}{\omega_{n}}, \\
& M_{p}=V_{d c}\left(t_{p}\right)-V_{d c}^{*}=-f_{4}(\xi) \frac{I_{m a x}}{\omega_{n}},
\end{aligned}
$$

where $f_{3}(\xi)$ and $f_{4}(\xi)$ are given, respectively, as

$$
\begin{aligned}
& f_{3}(\xi)=\frac{1}{\sqrt{1-\xi^{2}}} \tan ^{-1}\left(\frac{\sqrt{1-\xi^{2}}}{\xi}\right) \\
& f_{4}(\xi)=\frac{1}{C \sqrt{1-\xi^{2}}} e^{-\xi f_{3}(\xi)} \sin \left(\sqrt{1-\xi^{2}} f_{3}(\xi)\right) .
\end{aligned}
$$

The required time for the DC-link voltage to return back to the reference voltage is defined as the response time, $t_{r a}$, and is given by

$$
t_{r a}=\frac{1}{\omega_{n}} \frac{\pi}{\sqrt{1-\xi^{2}}}=\frac{f_{5}(\xi)}{\omega_{n}},
$$

where $f_{5}(\xi)$ is given as

$$
f_{5}(\xi)=\frac{\pi}{\sqrt{1-\xi^{2}}}
$$

It can be realized that the overshoot and response time are reduced by increasing $\omega_{n}$ in (16) and (20), respectively. Thus, the PI-controller gains of the DC-link voltage controller in (7) and (8) should be suitably adjusted to obtain better dynamic performance.

\section{PROPOSED PI-FUZZY CONTROLLER}

To develop the proposed fuzzy logic-based PI controller, the second-order time-response of the DClink voltage control is divided into several regions: A1, A2, A3, and A4, as shown in Figure 3. The first region corresponds to the rise time period of the system, B1, at which the response equals the set point $V_{d c}^{*}$. The second region starts from the rise time $\mathrm{B} 1$ to the peak time $\mathrm{C} 1$. The third region $\mathrm{A} 3$, extends from the peak time to the time instant B2 at which the response equals the set point for the second time. Finally, the fourth region A4, extends from B2 to instant C2, at which the response reaches a local minimum. In each region, a control signal is designed to provide the desired dynamic performance. The value of the controller proportional gain $K_{p d c}$ should be suitably adjusted to provide the desired dynamic performance. The scenario taken for each region can be described as a Fuzzy logic if-then-rule to conclude the PI-controller gains. It is required to simplify the controller as well as stabilize the DC-Link voltage immediately under sudden loads or supply changes. For this reason, the proportional gain $K_{p d c}$ can be only designed using if-then-rules while keeping $K_{i d c}$ fixed. This method of changing $K_{p d c}$ only has been utilized in [20].

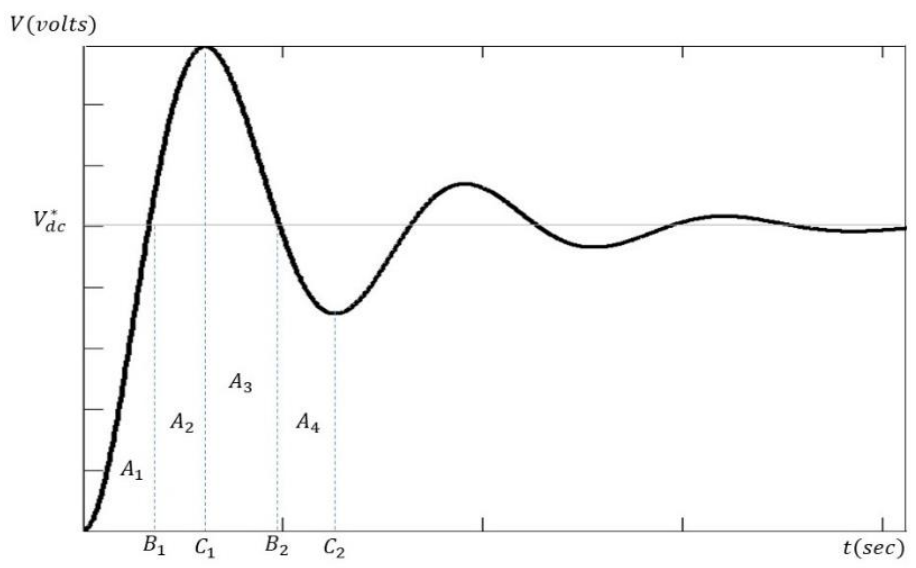




\subsection{Fuzzy Logic Controller}

Figure 3. General second order time-response of the DC-link controller.

The proposed controller is fuzzy logic-based PI controller in which suitable proportional gain is calculated depending on the region at which the response lies at any given time as illustrated in Figure 3. In general, the Fuzzy logic process consists of three main stages shown in Figure 4 [20]:

\subsubsection{Fuzzification:}

This process is responsible for assigning the crisp-values into membership of linguistic values. In this paper, the controller proportional gain is calculated based on two variables: the error $e(t)=\mathrm{V}_{\mathrm{dc}}(t)-V_{d c}^{*}$ and the change in error $\Delta e(t)$. The crisp values of each variable are fuzzified into $\mathrm{M}=3$ linguistic values: negative $(\mathrm{N})$, zero $(\mathrm{Z})$, and positive $(\mathrm{P})$ with different membership for each of them. In addition, five membership functions $(\mathrm{M}=5)$ : negative big $(\mathrm{NB})$, negative small $(\mathrm{NS})$, zero $(\mathrm{Z})$, positive small (PS), and positive big (PB) are also tested. The membership functions used for $\mathrm{M}=3$ and 5 are shown in Figure 5. It should be noted that the membership functions are Trapezoidal and Bell-shaped for $\mathrm{M}=3$ and 5, respectively, are chosen based on comprehensive study proposed in [28].

\subsubsection{Inference System:}

This consists of applying or firing suitable if-then rules in order to determine suitable controller proportional gain $K_{p d c}$. If the input variables have 3 membership functions, the controller gain will assume 3 linguistic values: small (S), medium (M), and big (B). However, if 5 membership functions are used for the input variables, the controller gain will have 7 linguistic values: zero (Z), medium small (MS), small (S), medium (M), and big (B), medium big (MB), and very big (VB) as shown in Figure 5. In general, for M membership functions there are $M \times M$ if-then rules. These rules are given in Tables 1 and 2 , for $M=3$ and 5 , respectively.

\subsubsection{Defuzzification:}

This transforms the output of the fuzzy system into crisp values which corresponds to the proportional gain which is then used in the PI controller to control the dc link voltage.

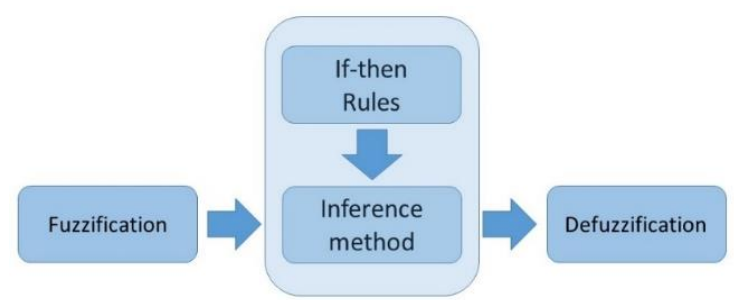

Figure 4. Structure of Fuzzy logic control system.

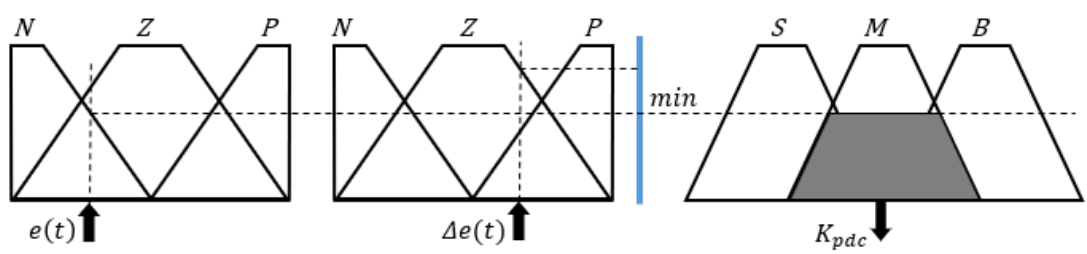

(a)

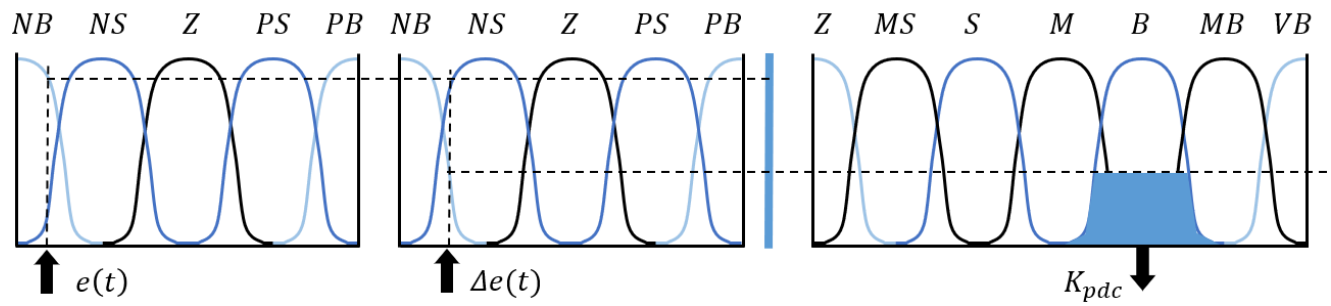

(b)

Figure 5. Linguistic values for the error (left), change in error (middle), their membership functions, as well as the linguistic values of the fuzzy logic output, i.e. the proportional controller gain, (right) for (a) $M=3$ and (b) $M=5$. 
Table 1. Nine if-then rules for fuzzy logic controller for $M=3$.

\begin{tabular}{cccc}
\hline $\boldsymbol{e}(\boldsymbol{t}) / \Delta \boldsymbol{e}(\boldsymbol{t})$ & $\boldsymbol{N}$ & $\boldsymbol{Z}$ & $\boldsymbol{P}$ \\
\hline $\boldsymbol{N}$ & $\boldsymbol{B}$ & $\boldsymbol{S}$ & $\boldsymbol{S}$ \\
$\boldsymbol{P}$ & $M$ & $\boldsymbol{M}$ & $\boldsymbol{B}$ \\
\hline
\end{tabular}

Table 2. Twenty-five if-then rules for fuzzy logic controller for $M=5$.

\begin{tabular}{cccccc}
\hline$e(t) / \Delta e(t)$ & $N B$ & $N S$ & $Z$ & $P S$ & $P B$ \\
\hline$N B$ & $\boldsymbol{V} \boldsymbol{B}$ & $\boldsymbol{V} \boldsymbol{B}$ & $\boldsymbol{V} \boldsymbol{B}$ & $\boldsymbol{V} \boldsymbol{B}$ & $\boldsymbol{V} \boldsymbol{B}$ \\
$N S$ & $\boldsymbol{B}$ & $\boldsymbol{B}$ & $\boldsymbol{B}$ & $\boldsymbol{V} \boldsymbol{B}$ \\
$Z$ & $\boldsymbol{Z}$ & $\boldsymbol{Z}$ & $\boldsymbol{Z}$ & $\boldsymbol{S} \boldsymbol{B}$ & $\boldsymbol{V} \boldsymbol{B}$ \\
$P S$ & $\boldsymbol{V} \boldsymbol{B}$ & $\boldsymbol{V} \boldsymbol{B}$ & $\boldsymbol{M} \boldsymbol{B}$ & $\boldsymbol{B}$ \\
\hline$B$ & $\boldsymbol{B}$ & $\boldsymbol{B}$ & $\boldsymbol{B}$ & \\
\hline
\end{tabular}

\subsection{Proposed PI-Fuzzy Controller}

In this paper, a PI-Fuzzy controller for DC-link voltage control is proposed. In the proposed system, the integral gain $K_{i d c}$ is fixed and found using (8) with $\omega_{n}$ chosen according to [17], while the value of the proportional gain, $K_{p d c}$, is calculated based on the rules of the fuzzy logic inference system presented in Tables 1 and 2. Moreover, an anti-windup mechanism adapted from [29] where four types of anti-windup methods are described (i.e. Back-calculation, Dow, Foxboro, and Belvins) and each of them has its own circuitry and parameters evaluated to compare there effectiveness according to different systems. So, a back-calculation method is carefully modified in connections and parameters to suit the proposed PI-Fuzzy controller in order to keep the integral action at a suitable value when the actuator saturates in order to avoid integral windup problem which causes large oscillations in the response of the system and large settling time.

The block diagram of the closed-loop DC-link voltage control using the proposed PI-Fuzzy controller is shown in Figure 6. The detailed structures of the proposed controller and anti-windup mechanism are illustrated in Figure 7 (a) and (b), respectively.

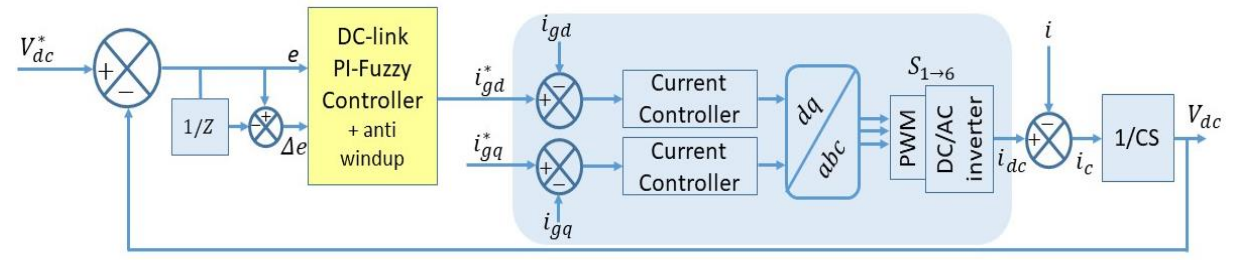

Figure 6. Proposed PI-Fuzzy controller for the DC-link voltage.

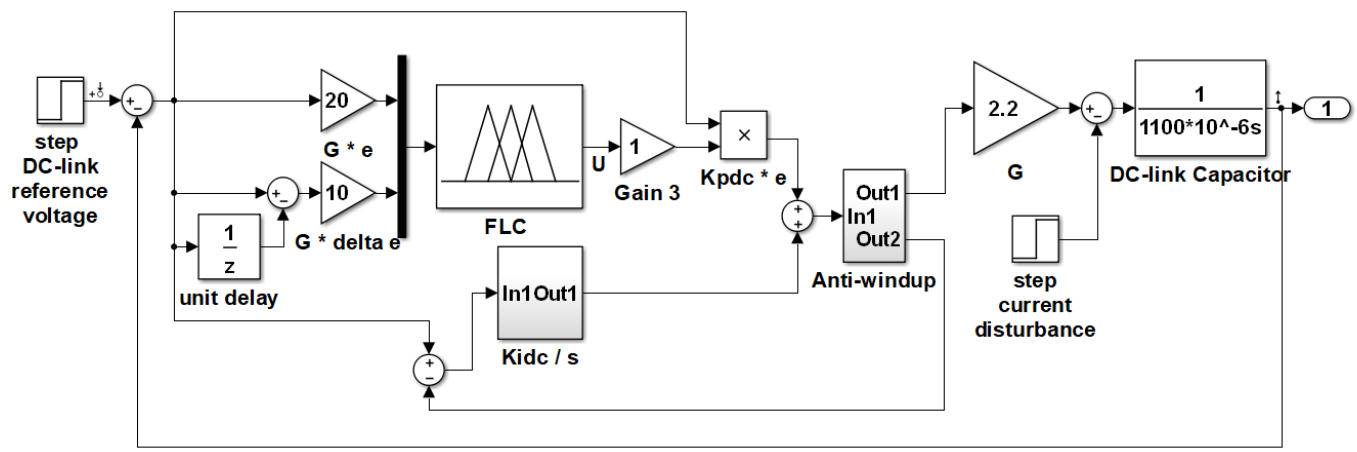

(a)

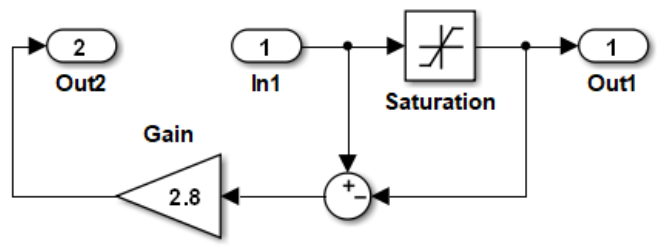

(b) 
Figure 7. Simulink models for: (a) the proposed PI-Fuzzy controller for the DC-link voltage and (b) the anti-

\subsection{Simulation results}

windup mechanism.

In order to evaluate the dynamic performance of the proposed PI-Fuzzy controller (including the antiwind-up mechanism), simulation experiments are performed in order to compare the proposed controller with two PI-controllers proposed in the literature for the DC-link voltage control. The first is a standard PI-controller with $\omega_{\mathrm{n}}=\omega_{\min }=21.99 \mathrm{rad} / \mathrm{sec}$ and $\omega_{\mathrm{n}}=\omega_{\mathrm{opt}}=34.74 \mathrm{rad} / \mathrm{sec}$ suggested in [17]. The controller gains, $K_{p d c}$ and $K_{i d c}$ are calculated using (7) and (8). The second is the adaptive PI-controller proposed in the same paper [17].

Simulation results are shown for two consecutive steps in the reference voltage, $\mathrm{V}_{d c}$ of $100 \mathrm{~V}$ and $150 \mathrm{~V}$, respectively, followed by a step of $i_{\text {dis }}=1.25 \mathrm{~A}$ in disturbance current. The parameters used in the simulation are given in Table 3. It should be noted that we define the rise-time in our paper, $t_{r}$, as the time required for the DC-link voltage to reach $99 \%$ of its reference value which is $150 \mathrm{~V}$. Also, we define $t_{r a}$ as the time required to return back to $99 \%$ of reference voltage after DC-link voltage drops due to the disturbance in current resulted from load variations according to (20).

Table 3. Simulation Parameters.

\begin{tabular}{ccc}
\hline Symbol & Description & Value \\
\hline$C$ & DC-link capacitor & $1100(\mu \mathrm{F})$ \\
$K_{i d c}$ & Proposed PI-Fuzzy integral gain & 6 \\
$i_{d i s}$ & Disturbance Current & $\{0.65,1.25\}(\mathrm{A})$ \\
$V_{d c}^{i n i t}$ & DC-link voltage initial step value & $\{0,100\}(\mathrm{V})$ \\
$V_{d c}^{*}$ & DC-link voltage reference value & $150(\mathrm{~V})$ \\
$G$ & Ratio between $i_{g d}^{*}$ and $i_{d c}^{\text {mean }}$ & 2.2 \\
$G_{a n t i}$ & Anti-windup gain & 2.8 \\
FIS & Fuzzy inference system for FLC & Mamdani \\
MF & Membership function for FLC & $M=\{3,5\}$ \\
Im & Implication for FLC & Min \\
$D_{\text {fuz }}$ & Defuzzification method & Centroid \\
\hline
\end{tabular}

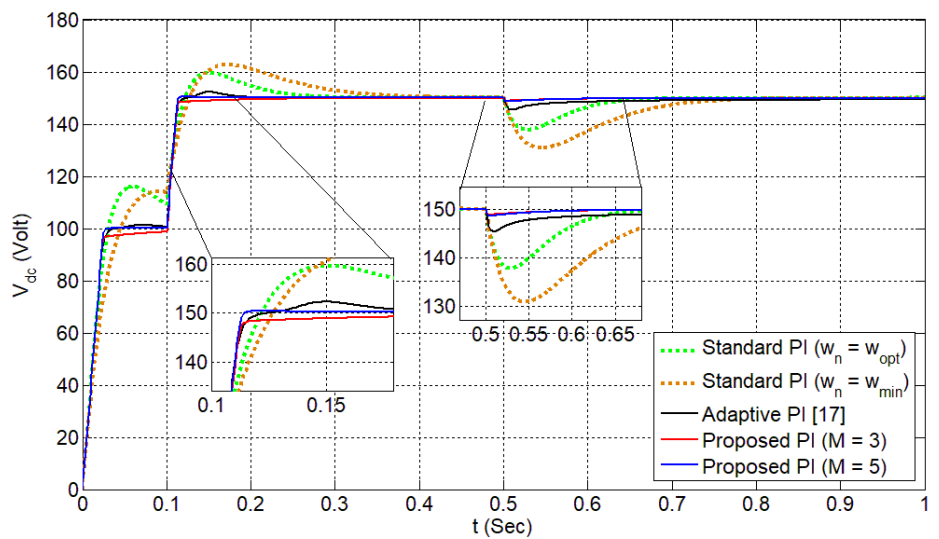

(a)

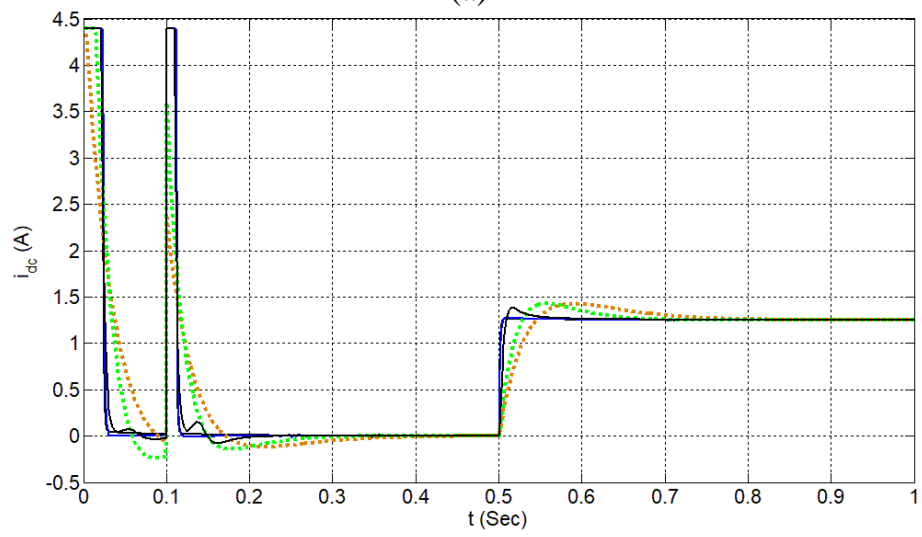

(b) 
Figure 8. Comparison of the proposed PI-Fuzzy controller (with $\mathrm{M}=3$ and $\mathrm{M}=5$ membership functions) with the standard PI-controllers (with $\omega_{\mathrm{n}}=\omega_{\min }$ and $\omega_{\mathrm{n}}=\omega_{\mathrm{opt}}$ ), and the adaptive PI-controller [17] for DC-link voltage control for $i_{d i s}=1.25 \mathrm{~A}$ and $V_{d c}^{\text {init }}=100 \mathrm{~V}$ : (a) Time-response, and (b) Control signal.

The time-responses and control signals for the DC-link voltage PI-controllers are shown in Figure 8 (a) and (b), respectively. As can be seen, the two proposed PI-Fuzzy controllers (i.e., $M=3$ and 5 membership functions) provide faster time-response at almost no over-shoot with the best rejection of disturbances in current. The rise time $t_{r}$ for the proposed PI-Fuzzy controllers for $\mathrm{M}=3$ and 5, and adaptive PI-controller in [17] are 21, 12.5 and 15.5, respectively. The proposed PI-Fuzzy controllers with $\mathrm{M}=3$ and 5 provide minimum DC-link voltage-drop $V_{\text {drop }} 0.733 \%$ and $0.867 \%$, respectively, compared to $3.066 \%$ for the adaptive PIcontroller proposed in [17].

It should be noted that the DC-link voltage-drop occurs due to the disturbance current, $i_{\text {dis }}$. Since the DC-link voltage drop provided by the proposed PI-Fuzzy controller still within $99 \%$ of $V_{d c}^{*}$, we can consider that the $t_{r a}$ is negligible. On the other hand, the adaptive PI-controller in [17] requires $96 \mathrm{mSec}$ to returns to $99 \%$ of $V_{d c}^{*}$.

Table 4 summarizes the performance indices for all PI-controllers considered in the simulation. It worth noting that the control signals for all PI-controllers, depicted in Figure 8(b), are within the same range. Hence, the better performance obtained with the proposed controller is not achieved with excessive control signal. In addition, the use of more linguistic values (i.e. $M=5$ membership functions) results in marginal improvement in performance. In summary, he proposed PI-Fuzzy controllers provide the best overall dynamic performance among the PI-controllers considered in the simulation.

Table 4. Performance indices for the proposed PI-Fuzzy controller (with $M=3$ and $M=5$ ) with the standard PI-controllers (with $\omega_{\mathrm{n}}=\omega_{\min }$ and $\omega_{\mathrm{n}}=\omega_{\mathrm{opt}}$ ), and the adaptive PI-controller [17] of DC-link voltage for $i_{\text {dis }}=1.25 \mathrm{~A}$ and $V_{d c}^{\text {init }}=100 \mathrm{~V}$.

\begin{tabular}{lllll}
\hline & $t_{r}(0 \rightarrow 99 \%)(\mathrm{mSec})$ & $\% M_{p}$ & $\% V_{\text {drop }}$ & $t_{\text {ra }}$ after $V_{\text {drop }}(\mathrm{mSec})$ \\
\hline Standard PI $\left(\omega_{n}=\omega_{\text {min }}\right)$ & 25 & $8.53 \%$ & $12.73 \%$ & 232 \\
Standard PI $\left(\omega_{n}=\omega_{\text {opt }}\right)$ & 20 & $6.4 \%$ & $8.13 \%$ & 130 \\
Adapt PI [17] & 15.5 & $1.53 \%$ & $3.066 \%$ & 96 \\
Proposed PI $(M=3)$ & 21 & - & $0.733 \%$ & - \\
Proposed PI $(M=5)$ & 12.5 & $0.26 \%$ & $0.867 \%$ & - \\
\hline
\end{tabular}

It should be noted that all simulation comparisons are carried out for the same DC-Link capacitor size at the same disturbances scenarios and step response reference voltage changes; also, the control signals are measured for all controllers under the study to show that the best performance is not on the expense of large control signal value. Hence, the carried out simulation study shows the superiority of the proposed PI-Fuzzy controller with an anti-windup mechanism than other controllers in literature to stabilize DC-Link voltage under step input and disturbance changes.

\section{CONCLUSION}

In this paper, a detailed mathematical formulation of the DC-Link voltage controller using PI controllers is derived. a PI-Fuzzy controller with the anti-windup mechanism is proposed to control the DClink voltage of the solar energy system. In the proposed controller, the integral gain is kept fixed, while the proportional gain is calculated based on a fuzzy logic inference system. The dynamic performance of the proposed controller is evaluated and compared with two PI controllers proposed in the literature. The proposed controller provides very promising results with almost no over-shoot in the step response with very small risetime and very good disturbance rejection.

As a possible future extension to the current work, it is interesting to modify the controller so that both controller gains can be adjusted using fuzzy logic rules. Moreover, the proposed controller can apply to other parts of renewable energy systems (e.g. build a fuzzy controller to minimize the offset voltage and scaling errors of analog to digital converter (ADC) described in [7] to maximize the power system efficiency. It is more interesting to carry this comparison study experimentally in the future to validate the proposed controller on a real system.

\section{REFERENCES}


[1] S.A. Khajehoddin, M. Karimi-Ghartemani, P.K. Jain, and A. Bakhshai, "DC-bus design and control for a single phase grid connected renewable converter with a small energy storage component," IEEE Trans. Power Electron., vol. 28, no. 7, pp. 3245-3254, Jul. 2013.

[2] M. Karimi-Ghartimani, S.A. Khajehoddin, P. Jain, and A. Bakhshai, "A systematic approach to dc-bus control design in single phase grid connected renewable converters," IEEE Trans. Power Electron., vol. 28, no. 7, pp. 31583166, July. 2013.

[3] X. Yuan, F. Wang, D. Boroyevich, Y. Li, and R. Burgos, "Dc-link voltage control of a full power converter for wind generator operating in weak-grid systems," IEEE Trans. Power Electron., vol. 24, no. 9, pp. 2178-2192, Sep. 2009.

[4] Li, F., Zou, Y.P., Wang, C.Z., Chen, W., Zhang, Y.C., Zhang, and J., "Research on AC Electronic Load Based on back to back Single phase PWM Rectifiers," Applied Power Electronics Conference and Exposition, APEC. Twenty-Third Annual IEEE, pp.630-634. 2008.

[5] J. Alcala, E. Barcenas and V. Cardenas, "Practical methods for tuning PI controllers in the dc-link voltage loop in back-to-back power converters," IEEE CIEP Power Electronics Congress, pp.46-52, San Luis Potosi, Mexico, August 2010.

[6] D. Casadei, M. Mengoni, G. Serra, A. Tani, and L. Zarri, "A control scheme with energy saving and dc-link overvoltage rejection for induction motor drives of electric vehicles," IEEE Trans. Ind. Appl., vol. 46, no. 4, pp. 1436-1446, Jul./Aug. 2010.

[7] QN. Trinh, FH. Choo, P. Wang, "Control Strategy to Eliminate Impact of Voltage Measurement Errors on Grid Current Performance of Three-Phase Grid-Connected Inverters," IEEE Trans. Ind. Elec., vol. 64, no. 9, pp. 75087519. doi: $10.1109 /$ tie.2017.2682029

[8] B. Gu and K. Nam, "A dc-link capacitor minimization method through direct capacitor current control," IEEE Trans. Ind. Appl., vol. 42, no. 2, pp. 573-581, Mar./Apr. 2006.

[9] D. Salomonsson, and A. Sannino, "Comparative design and analysis of de link voltage controllers for grid connected voltage source converter," IEEE Industry Applications Conference, pp.1593-1600, Louisiana, USA, Sept. 2007.

[10] R.L. De Araujo Ribeiro, T. De Oliveira Alves Rocha, R. Maciel de Sousa, E.C. Dos Santos Junior, and A.M. Nogueira Lima, "A robust dc-link voltage control strategy to enhance the performance of shunt active power filters without harmonic detection schemes," IEEE Trans. Ind. Electron., vol. 62, no. 2, pp. 803-813, Feb. 2015.

[11] W. H Choi, C. S Lam, M. C Wong and Y. D Han, "Analysis of DC-link voltage controls in three-phase four-wire hybrid active power filters," IEEE Transactions on Power Electronics, vol. 28, no. 5, pp. 2180-2191, August 2012.

[12] L. Chi-Seng, W. Man-Chung, C. Wai-Hei, C. Xiao-Xi, M. Hong-Ming, and L. Jian-Zheng, "Design and performance of an adaptive low dc-voltage controlled LC hybrid active power filter with a neutral inductor in threephase four-wire power system,” IEEE Trans. Ind. Electron., vol. 61, no. 6, pp. 2635-2647, June. 2014.

[13] S. Eren, M. Pahlevani, A. Bakhshai, and P. Jain, "An adaptive droop DC bus voltage controller for a grid connected voltage source inverter with LCL filter," IEEE Trans. Power Electron., vol. 30, no. 2, pp. 545-560, Feb. 2015.

[14] A. L. Elshafei and M. A. Azzouz, "Adaptive fuzzy regulation on the dc-bus capacitor voltage in a wind energy conversion system (WECS)," Expert Systems with Applications 38, ELSEVIER, pp.5500-5506, 2011.

[15] A. Luo, X.-Y. Xu, L. Fang, H.-H. Fang, J.-B. Wu, and C.-P. Wu, "Feedback-feedforward PI-type iterative learning control strategy for hybrid active power filter with injection circuit," IEEE Trans. Ind. Electron., vol. 57, no. 11, pp. 3767-3779, Nov. 2010.

[16] Dong-Choon L., G-Myoung L., and Ki-Do L., "DC-Bus Voltage Control of Three-Phase AC/DC PWM Converters Using Feedback Linearization”, IEEE Trans. on Industry Applications, vol.36, pp. 826- 833. 2000.

[17] Merai M., Naouar M. W., and Slama-Belkhodja I. "An Improved DC-Link Voltage Control Strategy for Grid Connected Converters", IEEE Transactions on Power Electronics, 33(4), 3575-3582. doi:10.1109/tpel.2017.2707398(2018)

[18] H. Anantwar, D. B. R. Lakshmikantha, S. Sundar, "Fuzzy self tuning PI controller based inverter control for voltage regulation in off-grid hybrid power system," Energy Procedia, 117, pp. 409-416. doi:10.1016/j.egypro.2017.05.160

[19] G. Soni, H. Singh, "Designing of Fuzzy logic controller for Set-point weight tuning of PID Controllers-", International Journal of Hybrid Information Technology, Vol 8, No.10, pp. 351-358, 2015

[20] K. Sharma, M. Ayyub, S. Saroha, and A. Faras "Advanced Controllers Using Fuzzy Logic Controller (FLC) for Performance Improvement," International Electrical Engineering Journal (IEEJ) vol. 5, no.6, pp. 1452-1458 ISSN 2078-2365, 2014.

[21] E. Natsheh, K. A. Buragga, "Comparison between conventional and fuzzy logic PID controllers for controlling DC motors", International Journal of Computer Science Issues, IJCSI, Vol 7, Issue 5, Sept.2010

[22] S. Khajehoddin, A. Bakhshai, P. Jain, and J. Drobnik, "A robust power decoupler and maximum power point tracker topology for a grid-connected photovoltaic system," in Proc. IEEE Power Electron. Spec. Conf., pp. 66-69, Jun. 2008.

[23] S. Khajehoddin, P. Jain, and A. Bakhshai, "Inverter for a distributed power generator," U.S. Patent App. 12/709 166.

[24] F. Shinjo, K. Wada, and T. Shimizu, "A single-phase grid-connected inverter with a power decoupling function," in Proc. IEEE Power Electron. Special. Conf., pp. 1245-1249, Jun. 2007.

[25] Q. Li and P. Wolfs, "A review of the single phase photovoltaic module integrated converter topologies with three different dc link configurations," IEEE Trans. Ind. Electron., vol. 23, no. 3, pp. 1320-1333, May 2008.

[26] F. Blaabjerg, R. Teodorescu, M. Liserre, and A. V. Timbus, "Overview of control and grid synchronization for distributed power generation systems," IEEE Trans. Ind. Electron., vol. 53, no. 5, pp. 1398-1409, Oct. 2006. 
[27] M-P. Kazmierkowski, and L. Malesani, "Current control techniques for three-phase voltage-source PWM converters: A Survey," IEEE Trans. Ind. Electron., vol. 45, no. 5, Oct. 1998.

[28] H. A. Ismail, A. Alenany, B. Abozalam, "Choosing Proper Membership Function of PI-Fuzzy Controller for DCLink Voltage," CiiT International Journal of Fuzzy Systems, Vol 11, No 3, PP 54 - PP 60, July - September 2019.

[29] E. Torstensson, "Comparison of Schemes for Windup Protection," M. Eng. thesis, Lund University, March 2013.

\section{BIOGRAPHY OF AUTHORS}

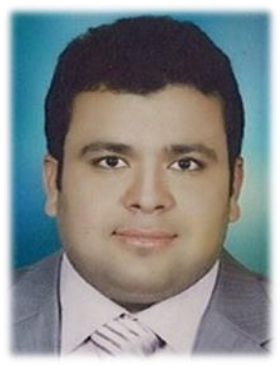

Husain A. Ismail was born in 1988 in Kuwait. He received his B.Sc. in industrial electronics and control engineering from Faculty of Electronic Engineering, Menoufiya University, Menoufiya, Egypt, in 2011. He is currently a demonstrator in Belbeis High Institute of Engineering, Sharkia, Egypt. He is also an M.Sc. student researcher in Computer and Systems Engineering at Zagazig University, Egypt.

His research interests are focused on the digital control of grid-connected converters and power quality improvement in the smart-grid applications.

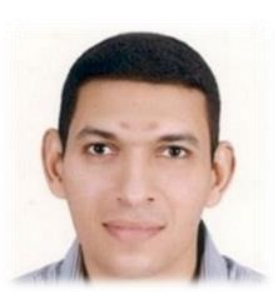

Ahmed Alenany received his Ph.D. Process Systems Engineering (Equivalent to Computer and Systems Engineering) from Faculty of Engineering, Laurentian University, Sudbury, ON, Canada, in 2012. He is currently an assistant professor with the department of Computer and Systems Engineering, Zagazig University, Egypt and the Faculty of Computer Science, Nahda University, Egypt, on part-time basis

His research interests are focused on the control engineering, system identification, machine learning, data mining, and pattern recognition. 